\title{
International web-based survey of informed consent procedures in genetic epidemiological studies: towards the establishment of a research coordinator accreditation system
}

\author{
Midori Yamamoto $^{1}$, Makiko Funamizu ${ }^{1}$, Kaori Muto ${ }^{2}$ and Akira Hata ${ }^{1,3}$ \\ We conducted an international web-based survey to obtain information about the informed consent (IC) procedures used in \\ genetic epidemiological studies of multifactorial diseases. In total, 53 responses from 15 countries were obtained. We found \\ that support personnel such as research coordinators took charge of a large part of the IC procedures, especially in the United \\ States. Although most support personnel had documented and/or verbal confidentiality agreements, and all had undertaken \\ IC training, accreditation examinations were only conducted in $60 \%$ of studies. Peripheral blood specimens were reported \\ to be a major source for DNA extraction, whereas noninvasive methods were used in some studies. To undertake high-quality \\ genetic epidemiological studies, participation of a large number of volunteers is essential for independent sets of samples that \\ allow confirmation of results. On the basis of the survey results obtained, support personnel dedicated to completing the IC \\ procedures are reported to be beneficial and indispensable in alleviating the burden on medical doctors, helping participants \\ to make autonomous decisions and promoting genome research. The establishment of a training program and accreditation \\ system for such personnel is warranted, especially in Japan, where medical staff usually finds it difficult to conduct IC \\ procedures in clinical settings due to heavy workloads.
}

Journal of Human Genetics (2009) 54, 713-720; doi:10.1038/jhg.2009.103; published online 30 October 2009

Keywords: genetic studies; IC; questionnaire; research coordinator; training program

\section{INTRODUCTION}

Owing to the rapid technological progress of human genetics and the establishment of human genome resources, genome-wide approaches have become feasible for identifying genes responsible for human multifactorial diseases. To take advantage of these achievements in clinical settings and preventive medicine, a large number of participants are required to confirm clinical validity in various ethnic groups when ethnic differences exist. Moreover, to detect and identify the genes responsible for multifactorial diseases such as diabetes, a large number of human specimens are necessary because of the low odds ratio of the various susceptibility alleles. Furthermore, results of genomic analyses must be verified using an independent human sample set and, therefore, collection of human specimens from a large number of volunteers in medical facilities and/or communities is indispensable in conducting this kind of study.

However, medical staff such as doctors and nurses, especially those in Japan, can find it difficult in the clinical setting to carry out proper informed consent (IC) procedures because of their heavy workloads, and these IC procedures are crucial for allowing potential volunteer participants to make autonomous decisions. In addition, study candidates may feel obliged not to refuse requests from medical staff who might be viewed as authoritarians.

Under these conditions, it is rational to suggest that support personnel specializing in IC are necessary for the collection of large numbers of human specimens in accordance with ethical guidelines. In Japan, it is noted by the Japanese Ministry in the 'Ethics Guidelines for Human Genome/Gene Analysis Research'1 (revised in 2005) that the principal investigator can have support personnel perform the necessary practice regarding IC, and should provide opportunities for on-the-job training to the support personnel. However, research groups are required to obtain IC on their own accord. As a result, each group has their own guidelines and procedures, with no concerted criteria outlined so far. To overcome these issues, the establishment of a qualification and accreditation system to promote genetic epidemiological studies would likely be mandatory under ethically proper circumstances.

As an initial step to construct such a system, we conducted an international survey of IC procedures carried out in overseas genetic

${ }^{1}$ Department of Public Health, Graduate School of Medicine, Chiba University, Chiba, Japan; ${ }^{2}$ Department of Public Policy, Human Genome Center, Institute of Medical Science, The University of Tokyo, Tokyo, Japan and ${ }^{3}$ Center for Preventive Medical Science, Chiba University, Chiba, Japan 
epidemiological studies. Rather than carrying out a simple international comparison of IC procedures, the purpose of this survey was to gather information about the use of support personnel to establish a new qualification system for genome medical research coordinators in Japan. For this purpose, we used a questionnaire to clarify the conditions of subject recruitment, the obtainment of IC and the collection of personal information, including specimens for DNA extraction.

\section{MATERIALS AND METHODS}

Respondents were selected from studies that aimed at genetic analyses of multifactorial diseases and which were published in a medical journal with a considerably high impact factor (>5.0) from January 2005 to January 2008. The invitation to participate was sent by e-mail and responders accessed the questionnaire form by connecting to the designated URL. The actual questionnaire used is shown in the Supplementary Figure.

An e-mail invitation was sent to 693 authors (of 686 articles) in 25 countries, and responses corresponding to 53 articles from 15 countries were obtained, almost $50 \%$ of these being from the United States (Table 1). A wide range of diseases was represented in the 53 studies, including cardiovascular diseases, malignant tumors, immune abnormalities, neurological diseases, ophthalmological diseases, skeletal diseases and skin diseases. Additional questionnaires regarding the personnel who carried out IC procedures were sent to 20 respondents by e-mail, of whom nine responded.

\section{RESULTS}

\section{Recruitment of study subjects}

In all, 40 of 53 respondents reported that doctors or nurses directly recruited participants for their studies. On the other hand, online recruitment and mass media were used in several cases when community-based volunteers were required. The postal service or telephone calls were used in four studies; however, this number might not be accurate as the answers were not included in the questionnaire multiple-choice items but were responses considered as other free answers (Supplementary Figure). Although the questionnaire answer of 'other/unclear' might indicate large population-based studies, family-based studies or recruitment through patient associations, it is conceivable that recruitment might have been by the postal service or telephone call (Figure 1a).

\section{Location where IC was obtained}

Of the 53 respondents, 43 answered that IC was obtained in the hospital or clinic, and 22 answered in the participant's home. A few face-to-face IC procedures were undertaken in meeting places or research centers. Contact was also made by telephone calls, mail or e-mail for subjects in four studies who were unable to visit the IC procedure location (Figure $1 \mathrm{~b}$ ).

\section{Qualifications of personnel in charge of obtaining IC}

In 20 of 53 responses, support personnel were engaged in obtaining IC. Most of these responses came from studies conducted in the United States (Figure 1c). The support personnel included the research coordinator, study recruiter, interviewer, research assistant, and student or professionals other than medical doctors, nurses, genetic counselors or $\mathrm{PhD}$ doctorates. Of these 20 studies, 12 revealed that support personnel took charge of IC procedures for $90-100 \%$ of participants in each study (Table 2a). By contrast, nurses were engaged in IC procedures in all six studies conducted by researchers in the United Kingdom (Figure 1c). Medical doctors were involved in the IC procedures in many studies (Figure 1c), which appeared to be conducted in hospitals or clinics. In all studies except one, no doctors took sole charge of the procedures in the patient's home, but other staff shared the tasks (Figure 2a).
Table 1 Number of authors invited and who responded to survey on a country-by-country basis of first author's institutional affiliation

First author's institutional affiliation

\begin{tabular}{|c|c|c|c|c|}
\hline Area & Country & $\begin{array}{c}\text { Number of } \\
\text { authors invited }\end{array}$ & $\begin{array}{l}\text { Number of } \\
\text { responses }\end{array}$ & $\begin{array}{c}\text { Response } \\
\text { rate (\%) }\end{array}$ \\
\hline \multirow[t]{6}{*}{ Asia } & China & 25 & 1 & 4.0 \\
\hline & Hong Kong & 3 & 0 & 0.0 \\
\hline & India & 4 & 1 & 25.0 \\
\hline & Korea & 15 & 1 & 6.7 \\
\hline & Singapore & 3 & 0 & 0.0 \\
\hline & Taiwan & 5 & 1 & 20.0 \\
\hline \multirow[t]{15}{*}{ Europe } & Austria & 2 & 0 & 0.0 \\
\hline & Belgium & 4 & 0 & 0.0 \\
\hline & Denmark & 16 & 0 & 0.0 \\
\hline & Finland & 19 & 0 & 0.0 \\
\hline & France & 19 & 1 & 5.3 \\
\hline & Germany & 48 & 4 & 8.3 \\
\hline & Iceland & 11 & 1 & 0.5 \\
\hline & Italy & 13 & 2 & 15.4 \\
\hline & Netherlands & 11 & 2 & 18.2 \\
\hline & Norway & 4 & 0 & 0.0 \\
\hline & Poland & 3 & 0 & 0.0 \\
\hline & Spain & 7 & 2 & 28.6 \\
\hline & Sweden & 31 & 0 & 0.0 \\
\hline & Switzerland & 2 & 0 & 0.0 \\
\hline & United Kingdom (UK) & 126 & 6 & 4.8 \\
\hline Middle East & Israel & 1 & 1 & 100.0 \\
\hline \multirow[t]{2}{*}{ North America } & Canada & 21 & 2 & 9.5 \\
\hline & United States (US) & 283 & 26 & 9.2 \\
\hline Oceania & Australia & 10 & 2 & 20.0 \\
\hline Total & 686 & 53 & 7.7 & \\
\hline
\end{tabular}

Two countries which each provided more than five separate questionnaires in response to the survey (darker shaded) and 13 other countries which each provided less than five questionnaires (lighter shaded) that were compared in Figure 1.

Regarding the size of the study population, almost all studies in which doctors took sole charge of the procedures consisted of $<2000$ subjects. By contrast, nurses and support personnel were engaged in studies of a larger subject size (Figure $2 b$ ).

Advantages of research coordinators performing the IC procedures Eight respondents expressed their views about the advantages of having the research coordinators perform the IC procedures. It was suggested that well-trained coordinators have a better understanding of IC procedures and study projects, and hence they can answer to the participant's questions more thoroughly than medical doctors, nurses and genetic counselors. They also have more available time to spend on IC procedures, incur lower costs than medical doctors and can alleviate any feelings of coercion the participants may feel in making their decision (Table 2b).

Confidentiality obligations of personnel in charge of obtaining IC Of the 20 studies in which support personnel were engaged in obtaining IC, 5 answered that the personnel worked in a profession that legally required them to maintain privacy, 11 answered that a privacy contract was agreed upon and 7 answered that the confidentiality of personal 
a

Personal contact from doctor/nurse in the hospital

In a meeting/seminar

Newspaper/magazine/TV/radio

On a website

Posting mail/phone call

Other/unclear
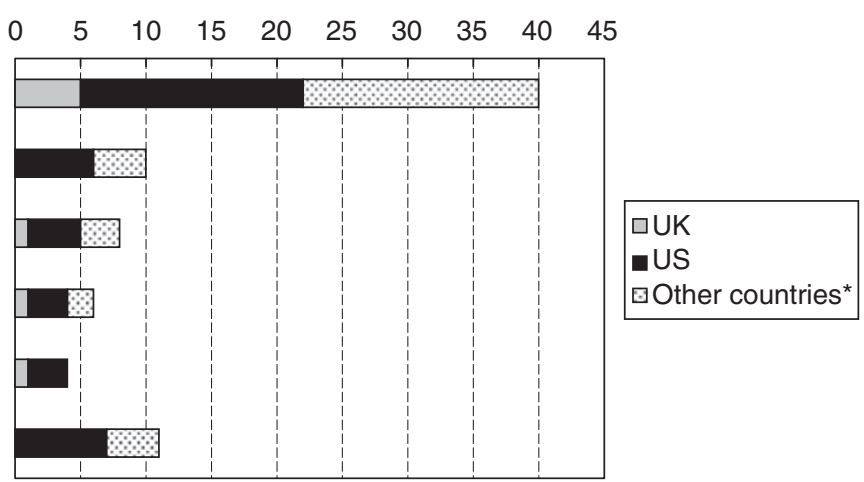

*Thirteen countries each with less than five separate questionnaires returned.

b

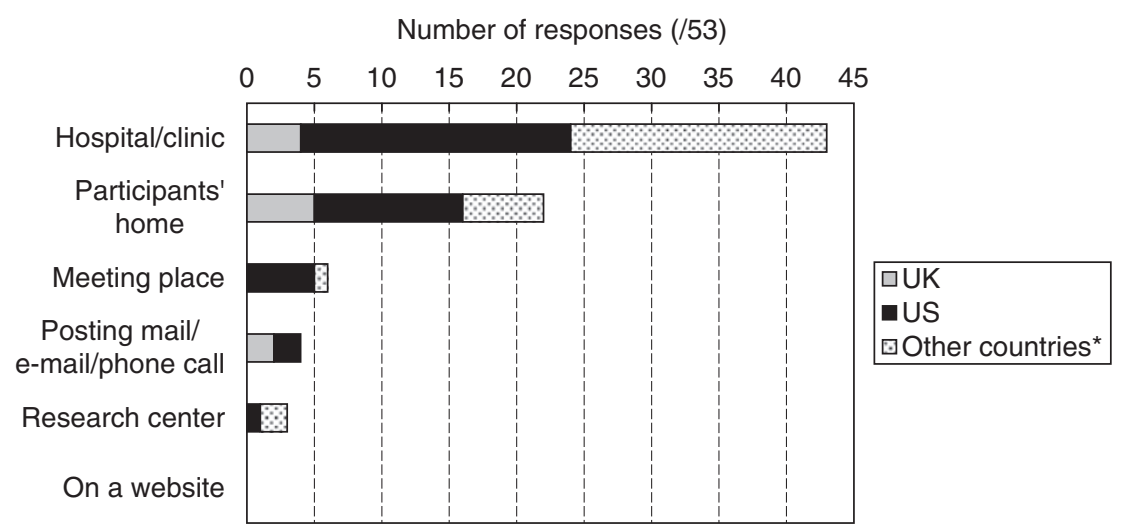

*Thirteen countries each with less than five separate questionnaires returned.

C

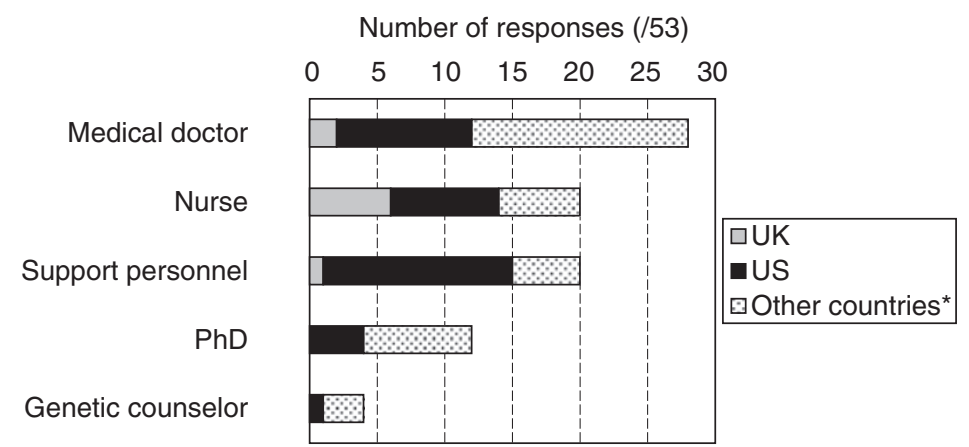

*Thirteen countries each with less than five separate questionnaires returned.

Figure 1 (a-c) Comparison between two countries, which each provided more than five separate questionnaires in response to the survey, and 13 other countries, which each provided less than five questionnaires. (a) Method for recruitment of study subjects (multiple answers allowed). (b) Location where IC was obtained (multiple answers allowed). (c) Qualification of personnel who obtained IC (multiple answers allowed).

data was simply confirmed verbally or through a training course (Figure 3a).

\section{Training programs and qualification tests for personnel in charge of} obtaining IC

In all 20 studies in which support personnel were engaged in obtaining IC, some on-the-job training was conducted, although qualification tests for accreditation were conducted on completion of a training course in only 12 of 20 studies (Figure $3 \mathrm{~b}$ ). Regarding the training issues of these 20 studies, 19 provided procedures for protection of human rights and 19 provided information on the research project. Other issues differed among study groups (Figure 3c).

\section{Specimens for DNA extraction}

In 45 of the 53 responses, the peripheral blood was collected from study subjects regardless of personnel qualifications of those in charge of obtaining IC. In few studies in which support personnel were involved in obtaining consent, other noninvasive methods such as saliva sampling, buccal smears and mouth washes were used as the source for DNA extraction (Figure 4).

\section{DISCUSSION}

To obtain specimens and personal data for genetic epidemiological studies, researchers must first recruit study participants, explain the study project and obtain the consent of the participants. We consider 
Table 2 (a) Qualification of personnel who obtained informed consent (IC) and frequency with which support personnel took charge of IC procedure; (b) Respondents' comments about the advantages of research coordinator over medical staff or genetic counselor in performing IC procedure (free-answer question)

Qualification of personnel who obtained informed consent

Support personnel

\begin{tabular}{|c|c|c|c|c|}
\hline $\begin{array}{l}\text { (a) } \\
\text { Country where subjects } \\
\text { were recruited }\end{array}$ & Hospital staff /research staff & $\begin{array}{c}\text { Research coordinator/ } \\
\text { recruiter/interviewer }\end{array}$ & Other support personnel & $\begin{array}{l}\text { Frequency with which } \\
\text { support personnel } \\
\text { took charge } \\
\text { (approximate \%) }\end{array}$ \\
\hline Canada & & $x$ & Lab technician & 95 \\
\hline Canada & & $\times$ & Lab technician & Unknown \\
\hline India & Medical doctor/nurse/PhD & & MSc (anthropology) & Unknown \\
\hline Israel & Medical doctor/nurse & & Research assistant & Unknown \\
\hline Netherlands/Australia & PhD & & Medical school student & Unknown \\
\hline UK & Medical doctor/nurse & & Psychologist & Unknown \\
\hline USA/UK & Medical doctor & $\times$ & & 100 \\
\hline USA & & $\times$ & & 100 \\
\hline USA & $\mathrm{PhD}$ & $x$ & Social worker & Unknown \\
\hline USA & & $\times$ & & 100 \\
\hline USA & & $\times$ & & 100 \\
\hline USA & Medical doctor/nurse/PhD & & Research students & 90 \\
\hline USA & & $x$ & & 100 \\
\hline USA & & $x$ & & 100 \\
\hline USA & Clinic staff & $x$ & & Unknown \\
\hline USA & Medical doctor/genetic counselor & $\times$ & & 100 \\
\hline USA & & $\times$ & & 100 \\
\hline USA & & $\times$ & & 100 \\
\hline USA & Medical doctor & $x$ & & Unknown \\
\hline USA & Nurse & $\times$ & & 100 \\
\hline
\end{tabular}

(b)

that the needs for support personnel who conduct these processes should increase in order to promote efficient epidemiological research. This international survey was conducted to comprehend the actual state of IC procedures in other countries so as to provide basic information for the establishment of training programs and accreditation systems for research coordinators. On the basis of the results obtained, we discuss below the need for research coordinators specializing in IC and suggest approaches for resource training.

In most countries, a request to participate in research was usually made by the hospital doctors or nurses (Figure 1a). This approach is effective as clinicians have often already established a rapport with the patient, and recruitment can take place subsequent to the medical consultation. When recruitment was conducted by post or telephone call, research coordinators were deemed helpful by the respondents. The three responses obtained for 'posting mail/ phone call' were from US researchers who used support personnel.

Support personnel are expected to be highly available in the process of explaining the study project and obtaining the consent of the participant. As seen in Figure 1c, support personnel obtained consent in more than half of the studies conducted in the United States (14 of 26 studies), as well as in several other countries. All these personnel also explained the study project (data not shown). A detailed breakdown of the support personnel in other countries was not available because of the limited number of responses. However, utilization of 

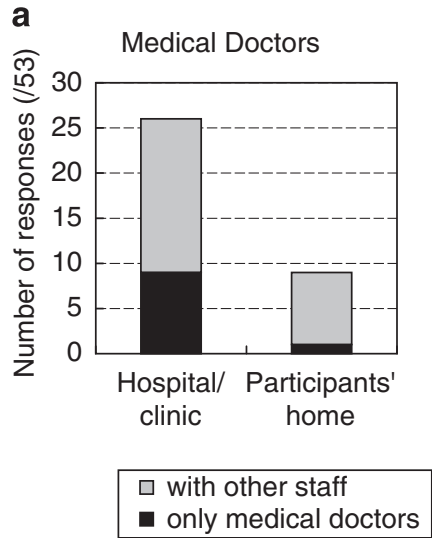
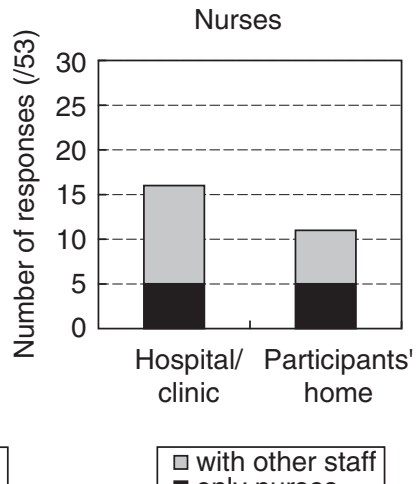
only nurses

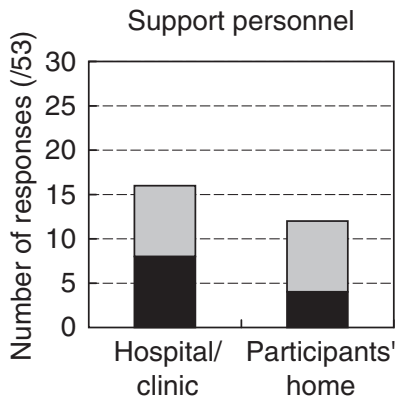

$\square$ with other staff

- only support personnel

b

Medical doctors
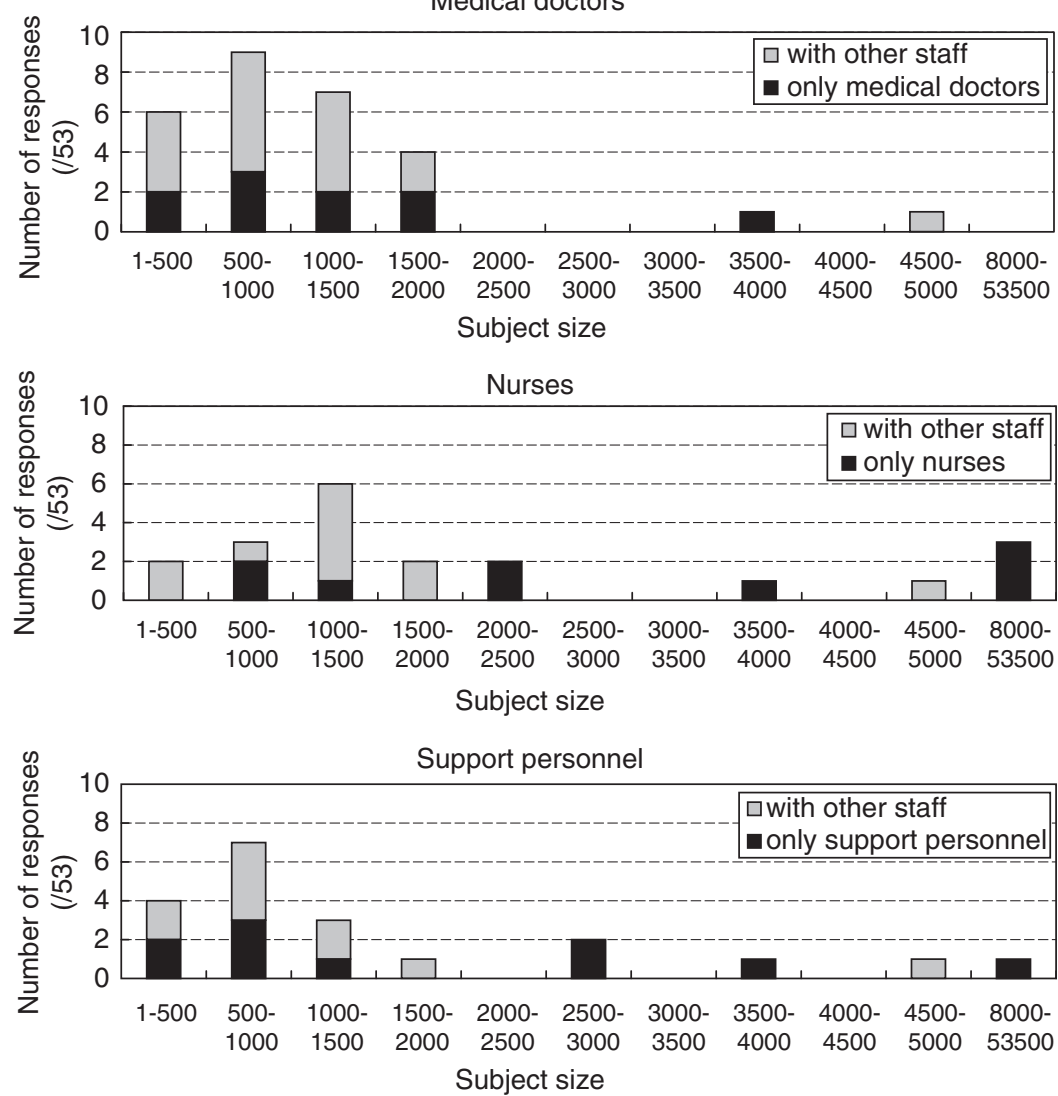

Figure 2 (a) Location where IC was obtained, comparing between hospital/clinic and patient's homes, relative to the qualification of personnel who obtained consent (multiple answers allowed). (b) Size of study population relative to the qualification of the personnel who obtained IC (multiple answers allowed).

support personnel was routinely performed in the United Statespresumably the most active country in genome-related research-and is expected to become common throughout other countries hereafter.

A major advantage of employing research coordinators in IC procedures is the sufficient time they can spend on the procedures. Thus, they can substitute for doctors and nurses in performing the procedures, while providing even more information required to possible participants. In 12 of 20 studies in which support personnel were employed, they took care of IC procedures for $90-100 \%$ of participants. Even though medical doctors were involved in IC procedures in seven studies, support personnel took charge of $>90 \%$ of the procedures in three of these studies (Table $2 \mathrm{a}$ ).
Moreover, medical doctors mainly performed such procedures with a relatively small number of participants (Figure $2 b$ ). These results are reasonable given that hospital doctors are fully occupied with their medical practice. By contrast, support personnel and nurses were involved in studies with large numbers of participants. In two studies carried out in the United Kingdom and one study in Iceland with 8000-53500 participants, nurses took sole charge of the IC procedures. This is not applicable to the current situation in Japan where most hospitals have a shortage of nurses. ${ }^{2}$ The number of practicing nurses per population in the United States, United Kingdom and Iceland is only slightly higher than in Japan, ${ }^{3}$ indicating that a shortage of nursing staff is a worldwide problem. In view of this, the high 
a

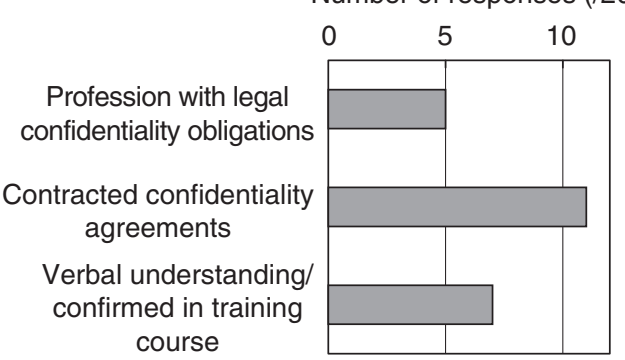

b

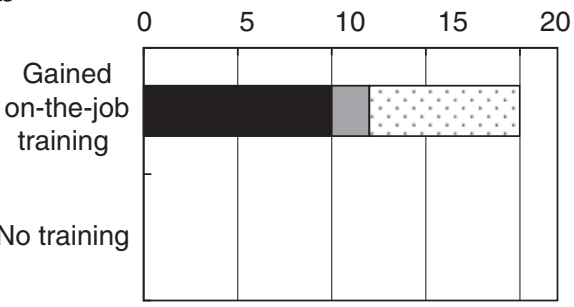

Written exam 0 Oral exam घ No exam

C

Number of responses (/20)

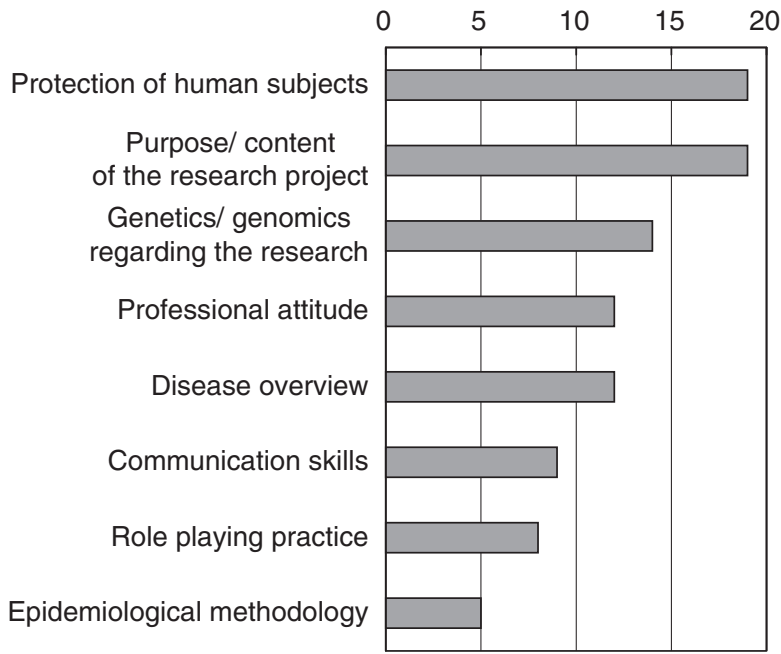

d

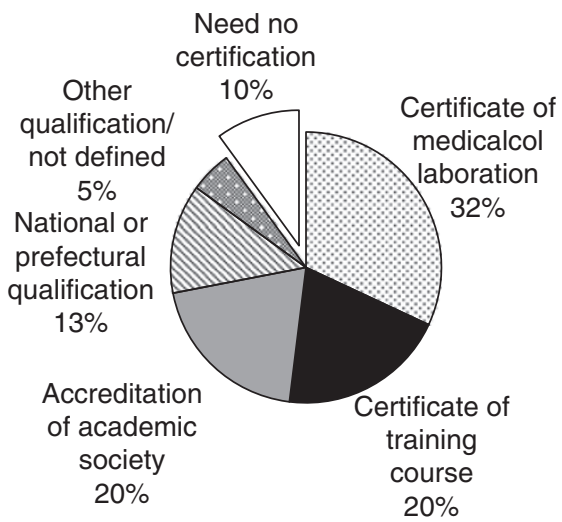

Figure 3 (a-c) Findings in 20 studies where support personnel other than doctors, nurses or genetic counselors were employed for IC procedures. (a) Confidentiality obligations to which personnel were bound (multiple answers allowed). (b) Attendance for on-the-job training and certification of personnel through examination. (c) Issues covered in personnel training course (multiple answers allowed). (d) Qualification required for Japanese research coordinators to perform their job.

utilization of nurses for IC procedures in the United Kingdom and Iceland was not attributed to sufficient human resources; rather it could be considered a strategic policy of the researchers. Under such circumstances, research coordinators can facilitate cooperation of hospital staff in the epidemiological studies. In our own experience in which DNA specimens have been collected under IC, the cooperation of hospital doctors would not be obtained without research coordinators who alleviate the burden on doctors.

Research coordinators can also arrange a convenient meeting time and place for study participants, making the IC process less onerous.
As seen in Figure 2a, no medical doctors took sole charge of consent procedures conducted at a patient's home; the only exception being a study conducted in Bangladesh by US researchers. Considering the importance of obtaining a family history in studies of genetic disorders, research staff may often need to visit family members.

The advantage of research coordinators was revealed with respect to the quality of IC procedures. As seen in Table 2b, some researchers who employ support personnel believe that they are more dedicated to IC-related study. Well-trained support personnel not only reduce the workload of hospital medical staff, but also understand privacy 


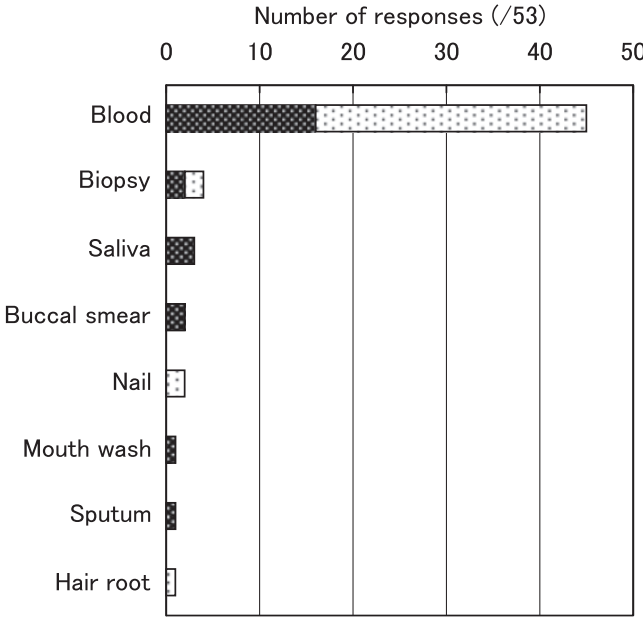

Gupport personnel involved

$\square$ No support personnel

Figure 4 Specimens for DNA extraction obtained from study subjects in all 53 studies (multiple answers allowed).

policies, IC procedures and research projects better than most medical staff, and thus are better able to answer to participant's questions and handle their anxiety and lack of understanding. This is essential for the potential participants to make their decision to participate in the study on the basis of sufficient information. ${ }^{4-6}$

Another advantage to the use of support personnel is that they promote the autonomy of participants, by not making them feel obliged to accept the request of medical staff to participate ${ }^{7}$ (Table 2). This feeling can occur in Western societies in which individualism prevails, but tends to occur more often in Japan where people do not like to act inharmoniously. As the Declaration of Helsinki ${ }^{8}$ states, the process of obtaining IC would be better conducted by a third person who has an independent relationship with the physician.

In employing research coordinators for IC procedures, there are certain matters to be considered. First, research coordinators should protect the privacy of study subjects. In our survey, most personnel in charge of IC were not licensed persons under legal confidentiality obligations, but rather they created a confidentiality agreement contract or confirmed confidentiality verbally (Figure 3a). The issue of human rights was included in 19 training courses conducted in 20 examined studies (Figure 3c). Personal information in genetic research is strictly required to be kept confidential. ${ }^{9-11}$ Furthermore, as most people are concerned about the leakage of personal information, epidemiological studies could be stopped if researchers do not protect such information. ${ }^{12}$ Hence, researchers should ensure that personal data are kept secret through anonymous handling of data and confidentiality obligations entered into by the support personnel. This is not only necessary for putting the subjects at ease, but also for gaining the trust of the hospital staff.

In Japan, according to 'Ethics Guidelines for Human Genome/Gene Analysis Research,' sons whose profession involves legal confidentiality obligations. Despite this, it is not easy to find enough people within such professions to conduct the specified work. The procedure in other countries where support personnel who are not certified persons are provided with contracted confidentiality agreements (Figure 3a) is considered appropriate.

Research coordinators should have the ability to provide sufficient information to study subjects, as previously mentioned. It was shown in 20 studies that all researchers offered on-the-job training for support personnel involved in the IC procedure (Figure 3b). In terms of the content of these training courses, 19 of the 20 studies included issues related to the research purpose. However, knowledge of human genetics and an overview of the disease were covered in only 14 and 12 studies, respectively (Figure 3c). Subjects are supposed to be given an explanatory document regarding the research project; however, written information tends to be difficult to understand ${ }^{4}$ and is often not read carefully. ${ }^{13,14}$ Moreover, some people feel insecure about genetic research itself. ${ }^{15}$ Accordingly, research coordinators are required to give sufficient and easy-to-understand explanations about the research.

Finally, an equally necessary qualification for research coordinators is the ability to communicate with an appropriate attitude. More than nine studies in our survey included training on these matters (Figure 3c). Most patients are likely to have some anxiety about their disease and possible concerns about privacy, their relationship with their family and social position. ${ }^{11,16}$ Moreover, coordinators are required to build a trustful relationship with hospital staff to gain cooperation in recruiting subjects and obtain clinical information.

An accreditation system for highly qualified research coordinators could also be helpful in gaining the cooperation of hospital staff and study subjects. Examinations for accreditation on completion of a training course were conducted in only 12 of 20 studies in this survey (Figure $3 \mathrm{~b}$ ). In another survey of 126 medical research coordinators in Japan, however, we found that $90 \%$ of coordinators wished to have some sort of certification (Figure 3d), and most suggested that the qualification should take into account communication skills and knowledge of the genetic research project and disease. A training program for fostering of research coordinators and accreditation criteria in Japan is therefore warranted to help improve these qualifications, and has already been launched by the Japan Society of Human Genetics.

The peripheral blood was the most commonly sampled human specimen used for DNA extraction, even when support personnel were engaged in obtaining IC (Figure 4). However, although blood is easy to collect in sufficient quantities, is free of bacterial DNA and has low material costs, it is also inconvenient for the following reasons. First, owing to legal restrictions, only doctors, nurses and other qualified persons are permitted to withdraw blood. Second, people often feel reluctant to undergo invasive sampling, especially under the guise of voluntary participation in a study that may only slightly benefit them.

Some research groups collected saliva, a buccal smear or mouth wash as well as blood (Figure 4). Given the fact that most research coordinators are likely to be unqualified at drawing blood and as the IC procedure is frequently conducted outside a hospital, these noninvasive methods are perhaps more useful than blood sampling. In particular, saliva sampling with a buffered stabilizing solution is noninvasive, has high-yield recovery and good storage stability. ${ }^{17}$ However, it is sometimes difficult to collect sufficient quantities of saliva depending on the intelligibility of the subject and dryness of the mouth. Accordingly, specimens should be collected in a coordinated manner, in view of the advantages of each method.

In general, we gathered sufficient information regarding the recruitment of subjects performed in other countries, IC procedures, and the collection of specimen and personal data during recent clinical genome research on multifactorial diseases. On the basis of the findings, we have identified the need for research coordinators skilled in IC procedures, and for adequate sample collection methods suitable for such personnel. We have also defined the qualifications that these research coordinators should possess. 
Unfortunately, the survey response rate $(7.7 \%)$ was low (Table 1). However, all of the target studies were critically evaluated and published in respected medical journals in the last three years, and thus it seems reasonable to suppose that the responses obtained from this survey were credible with respect to the ethical background of recent clinical genome studies worldwide. Furthermore, the principal purpose of this survey was information gathering to establish a new qualification system for Japanese research coordinators rather than an international comparison of IC procedures. In this respect, the information obtained was useful.

The growing popularity of genome-wide association studies suggests a need for research coordinators. Furthermore, as it is desirable for personnel to explain procedures in pharmacogenomics, establishment of a training program for research coordinators should be pursued.

\section{ACKNOWLEDGEMENTS}

This work was supported by a Grant-in-Aid for Scientific Research on priority area 'Applied Genomics' from KAKENHI, the Ministry of Education, Culture, Sports, Science and Technology, Japan.

1 Ministry of Economy, Trade and Industry, Ministry of Education, Culture, Sports, Science and Technology, and Ministry of Health, Labour and Welfare-Japan. Ethics Guidelines for Human Genome/Gene Analysis Research (2005) http://www.mext. go.jp/a_menu/shinkou/seimei/genome/04122801.htm.

2 Sawada, A. The nurse shortage problem in Japan. Nurs. Ethics 4, 245-252 (1997).

3 OECD Health Data (2008) http://www.oecd.org/department/0,3355,en_2649_34631 1_1_1_1_1,00.htm.
4 Cox, K. Informed consent and decision-making: patient's experiences of the process of recruitment to phases I and II anti-cancer drug trials. Patient Educ. Couns. 46, 31-38 (2002).

5 Kristman, V. L. \& Kreiger, N. Information disclosure in population-based research involving genetics: A framework for the practice of ethics in epidemiology. Ann. Epidemiol. 18, 335-341 (2007).

6 Länsimies-Antikainen, H., Pietilä, A.-M., Laitinen, T., Schwab, U ., Rauramaa, R . \& Länsimies, E. Evaluation of informed consent: a pilot study. J. Adv. Nurs. 59, 146-154 (2007).

7 Appelbaum, P. S., Lidz, C. W. \& Klitzman, R. Voluntariness of consent to research: a conceptual model. Hastings Cent. Rep. 39, 30-39 (2009).

8 World Medical Association Declaration of Helsinki, Ethical principles for medical research involving human subjects (1964), amended by the 59th WMA General Assembly, Seoul (2008)http://www.wma.net/e/policy/pdf/17c.pdf.

9 Porteri, C. \& Borry, P. A proposal for a model of informed consent for the collection, storage and use of biological materials for research purposes. Patient Eiduc. Couns. 71, 136-142 (2008).

10 United Nations Educational, Scientific and Cultural Organization (UNESCO). International declaration on human genetic data (2003) http://portal.unesco.org/en/ev.phpURL_ID=17720\&URL_DO=DO_TOPIC\&URL_SECTION=201.html.

11 Welch, C. A. Sacred secrets-the privacy of medical records. New Engl. J. Med. 345, 371-372 (2001).

12 Cyranoski, D. Dispute over data privacy halts cancer study. Nature 424, 359 (2003).

13 Cassileth, B. R., Zupkis, R. V., Sutton-Smith, K. \& March, V. Informed consent-why are its goals imperfectly realized? New Engl. J. Med. 302, 896-900 (1980).

14 Hoeyer, K. 'Science is really needed-that's all I know': informed consent and the nonverbal practices of collecting blood for genetic research in Northern Sweden. New Genet. Soc. 22, 229-244 (2003).

15 Matsui, K., Kita, Y. \& Ueshima, H. Informed consent, participation in, and withdrawal from a population based cohort study involving genetic analysis. J. Med. Ethics 31, 385-392 (2005).

16 Clayton, E. W. Ethical, legal, and social implications of genomic medicine. New Engl. J. Med. 349, 562-569 (2003).

17 Rogers, N. L., Cole, S. A., Lan, H. C., Crossa, A. \& Demerath, E. W. New saliva DNA collection method compared to buccal cell collection techniques for epidemiological studies. Am. J. Hum. Biol. 19, 319-326 (2007).

Supplementary Information accompanies the paper on Journal of Human Genetics website (http://www.nature.com/jhg) 